\title{
Comparison of Cardiorespiratory and Hormonal Responses between Sustained Constant and Alternating Intensity Exercise
}

\section{Spanoudaki ${ }^{1 *}$, Maridaki $\mathbf{M}^{1}$, Karatzanos $E^{2}$, Bogdanis GC ${ }^{1}$, Spanoudaki $C^{3}$ and Baltopoulos $\mathbf{P}^{1}$}

${ }^{1}$ Department of Sports Medicine \& Biology of Physical Activity, Faculty of Physical Education and Sports Science, National \& Kapodistrian University of Athens, 41 Ethnikis Antistasis, Dafni, Greece

${ }^{2}$ Cardiopulmonary Exercise Testing and Rehabilitation Laboratory, Evgenidio Hospital, School of Medicine, National \& Kapodistrian University of Athens, Greece, 20

Papadiamantopoulou Str., 115 28, Athens, Greece

${ }^{3}$ Neonatal Intensive Care Unit, General Hospital of Chania, Greece

\begin{abstract}
Background: Cardiorespiratory and hormonal responses were investigated during and after prolonged exercise of constant and alternating exercise intensity.
\end{abstract}

Methods: Ten healthy males underwent two main cycling exercise trials at the same overall power output, lasting one hour each. During the first trial, exercise intensity was constant at $70 \pm 5 \% \mathrm{VO}_{2 \max }$, while during the second trial, exercise intensity was alternated between $47 \pm 2 \% \mathrm{VO}_{2 \max }$ for $40 \mathrm{~s}$ and $120 \% \mathrm{VO}_{2 \max }$ for $20 \mathrm{~s}$.

Results: Oxygen uptake $\left(\mathrm{VO}_{2}\right)$ and heart rate $(\mathrm{HR})$ were higher in constant compared with alternating intensity exercise $\left(\mathrm{VO}_{2}: 32.5 \pm 6.6\right.$ vs. $29.8 \pm 5.9 \mathrm{ml} / \mathrm{kg} / \mathrm{min}, \mathrm{p}<0.05$; HR: $152 \pm 16$ vs. $\left.142 \pm 15 \mathrm{~b} / \mathrm{min}, \mathrm{p}<0.05\right)$. Pulmonary ventilation, respiratory exchange ratio and blood lactate were similar in both trials. Plasma adrenaline and growth hormone during and 1 hour after exercise were similar in both trials, while nor-adrenaline was higher during constant intensity exercise $(p<0.05)$. Significant time effects were found for all cardiorespiratory, lactate and hormonal parameters.

Conclusions: Constant and alternating intensity exercise of the same mean intensity and duration provoked similar changes in terms of stress and blood- lactate, while $\mathrm{VO}_{2}$ and $\mathrm{HR}$ responses and nor-adrenaline concentration were higher when exercise intensity was constant, suggesting that constant exercise impose greater demand on the cardiovascular system.

Keywords: Adrenaline; Noradrenaline; Growth hormone; Bloodlactate

\section{Introduction}

Alternating intensity exercise consists of repeated periods of intense exercise followed by periods of less intense exercise. This type of exercise is used in many sports activities and it has the advantage that high intensity can be sustained for longer period of time than during constant exercise, depending on exercise protocols (ratio of exercise- rest, intensity $[1,2]$. Furthermore, it is well established that alternating intensity training improves performance of athletes and sedentary populations [1]. Comparison of the two exercise patterns are important, as both types are used in sports training in order to facilitate physiological adaptations to improve performance.

A few studies have examined the acute cardiorespiratory and metabolic response in intermittent exercise in comparison to constant exercise. Some of these showed that maximal oxygen uptake $\left(\mathrm{VO}_{2}\right)$, pulmonary ventilation (VE), respiratory exchange ratio (R), and heart rate (HR) did not differ between the two exercise protocols [3-5], or found lower values [6-8] or were higher compared to intermittent exercise [9].

Also, there are only a few studies that examined and compared hormonal changes in terms of stress response between constant and intermittent exercise. Catecholamines (adrenaline, nor-adrenaline) are known to regulate important cardiorespiratory and metabolic functions [10]. Nieman et al. [11], showed that adrenaline concentration was the same after both exercise regimes using a cycle ergometer. Moreover, growth hormone $(\mathrm{GH})$ has been found to be either higher with intermittent exercise [12] or similar to constant [13].

Exercise at a high intensity results in an increase of $\mathrm{VO}_{2}$ and blood lactate concentration in a non - sustainable way. Thus, it may be expected that the hormonal responses to alternating exercise would differ from those observed during constant exercise, even if mean intensity is similar. We hypothesized that alternating intensity exercise would evoke larger cardiorespiratory and hormonal responses than constant exercise, implying that alternating exercise is more stressful and demanding.

To the best of our knowledge, there is no other study that compared cardiorespiratory, stress responses and blood lactate concentration between the two types of exercise, when power output and exercise duration are equal. Thus, the purpose of this study was to compare the cardiorespiratory and hormonal response in constant and alternating intensity exercise of the same duration and average intensity.

\section{Material and Methods \\ Participants}

Ten healthy moderately trained young men volunteered for the study (age: $24.7 \pm 4.7$ years, body mass: $78.5 \pm 8.9 \mathrm{~kg}$, height: $180.8 \pm 6 \mathrm{~cm}$, body fat: $9.1 \pm 3.1 \%$. Prior to commencement, approval was obtained from the Institutional Ethical Committee and all experimental procedures

*Corresponding author: Sofia S. Spanoudaki, Department of Sports Medicine \& Biology of Physical Activity, Faculty of Physical Education and Sports Science, National \& Kapodistrian University of Athens, Valtetsiou St, Vrilissia 15235, Athens Greece, Tel: 0030-2108103282; Fax: 0030-2109708367; E-mail: sspanoud@ yahoo.gr

Received September 09, 2011; Accepted January 06, 2012; Published January 10, 2012

Citation: Spanoudaki S, Maridaki M, Karatzanos E, Bogdanis GC, Spanoudaki C et al. (2012) Comparison of Cardiorespiratory and Hormonal Responses between Sustained Constant and Alternating Intensity Exercise. J Sport Medic Doping Studie 2:103. doi:10.4172/2161-0673.1000103

Copyright: ( 2012 Spanoudaki S, et al. This is an open-access article distributed under the terms of the Creative Commons Attribution License, which permits unrestricted use, distribution, and reproduction in any medium, provided the original author and source are credited. 
Citation: Spanoudaki S, Maridaki M, Karatzanos E, Bogdanis GC, Spanoudaki C, et al. (2012) Comparison of Cardiorespiratory and Hormonal Responses between Sustained Constant and Alternating Intensity Exercise. J Sport Medic Doping Studie 1:103. doi:10.4172/21610673.1000103

Page 2 of 6

conformed to the Declaration of Helsinki for experimentation with human participants. All participants were informed of all procedures and purposes of the study and gave their written informed consent.

\section{Experimental design}

Each participant completed three preliminary tests for a) measurement of $\mathrm{VO}_{2 \max }$, b)onset of blood lactate accumulation, and c) familiarization with the two main tests: I) constant and II) alternating intensity exercise protocol. These laboratory tests were conducted on five separate occasions. $\mathrm{VO}_{2 \max }$ and lactate threshold tests were conducted at least three days apart and no longer than a week. The two main tests were conducted one week apart in random order and took place at the same time of the day (at 6:00 am), so as to avoid alternations on performance because of circardian rhythm. Participants were fasted overnight and avoided exercise 2 days prior to the main tests. Also, they were asked to write down their food diary for the last 2 days before the first main test, and follow the same diet, so as to consume the same foods in both tests.

All tests $\left(\mathrm{VO}_{2 \max }\right.$, submaximal, Constant and Alternating intensity exercise) were conducted on the same modified, friction loaded cycle ergometer (Monark model, Sweden) in which a special alteration was made in order to run the alternating intensity exercise test. Specifically, a mechanical construction was affixed on the handles of the cycle ergometer and had the ability to change the workload of the cycle ergometer instantaneously with a flip of a switch. This operation was conducted manually by an assistant. Also, the cycle ergometer was equipped with a photocell, which monitored the velocity of the flywheel (122 black and white strips placed on the flywheel rim). The signal was amplified (Biopac Systems Inc) and stored on a computer. The calculation of power output was described elsewhere [14]. Shortly, Instantaneous flywheel velocity data were low pass filtered with a cut off frequency of $\mathrm{Hz}$ and flywheel acceleration was obtained by digital derivation. Flywheel inertia was calculated from deceleration measurements against different loads and power output was corrected for changes in kinetic energy of the flywheel. Values of power output and pedal rate were averaged over each pedal down stroke.

\section{Protocol of $\mathrm{VO}_{2 \max }$ and onset of blood lactate accumulation}

$\mathrm{VO}_{2 \max }$ was determined by continuous incremental cycling test to exhaustion with open circuit - spirometry (MedGraphics CPX/D, USA). The pedaling frequency was set at $70 \mathrm{rpm}$ and was maintained throughout the test. $\mathrm{VO}_{2 \max }$ was defined as the highest $\mathrm{VO}_{2}$ obtained in 30 seconds. Each participant was verbally encouraged to continue exercise until volitional exhaustion. The test was terminated when the participants met at least three of the following five criteria: a) a plateau in the $\mathrm{VO}_{2}$ vs. exercise intensity relationship, which has been defined as an increase in $\mathrm{VO}_{2}$ of less than $2 \mathrm{ml} / \mathrm{Kg} / \mathrm{min}$ with an increase in exercise intensity, b) R greater than $1.1, \mathrm{c}$ ) a final heart rate within $10 \mathrm{~b} / \mathrm{min}$ of the age predicted maximum, d) participants fatigue and e) a rating of perceived exhaustion (RPE) of 19-20 on the Borg scale. Prior to each test, the gas analyzers were calibrated, using gases of known $\mathrm{O}_{2}$ and $\mathrm{CO}_{2}$ concentrations.

Maximal Power Output (POmax) was defined as the highest average power output during the last minute of the $\mathrm{VO}_{2 \max }$ protocol.

During the onset of blood lactate accumulation test (OBLA), each subject performed 5 submaximal sets using the cycle ergometer, which each lasting 5 minutes and the frequency was set at $70 \mathrm{rpm}$. The pedaling frequency was maintained through both tests, with the aid of a digital display adjusted to the bike. In addition, an assistant was verbally giving feedback to the participants, to either speed up, slow down, or maintain the pedaling frequency. At the end of each set, $20 \mu \mathrm{l}$ of blood was taken from the participant's fingertip and diluted with $200 \mu \mathrm{l}$ percloric acid and then stored at $-20^{\circ} \mathrm{C}$ until the analysis was conducted. Determination of the OBLA (based on the $4 \mathrm{mmole} / \mathrm{l}$ method) was obtained from non-linear plots of exercise intensity (power) against lactate concentration [15]. Four hours before each test participants were told to refrain from consuming food, coffee and alcohol.

\section{Constant- alternating intensity protocol}

The duration of each test was 1 hour with the same mean intensity at $105 \%$ of the OBLA for both protocols. Alternating intensity exercise was a continuous protocol in which there was no rest period and intensity fluctuated in a repeating pattern. The exercise protocol has been explained in detail previously [16]. Shortly, during constant exercise $(\mathrm{CON})$, participants cycled at a power output corresponding to $105 \%$ of the OBLA $\left(69.8 \pm 4.7 \% \mathrm{VO}_{2 \max }\right)$. During alternating intensity exercise (ALT), 40 seconds of light exercise, $\left(46.5 \pm 1.9 \% \mathrm{VO}_{2 \max }\right)$, was alternated with 20 seconds intervals of hard cycling at $120 \%$ of $\mathrm{VO}_{2 \max }$ so as the mean intensity (power output) was the same. The intensity of both protocols was based on pilot studies in which intensities corresponding from $105 \%$ - 115\% OBLA were tested. The intensity corresponding to $105 \%$ OBLA was chosen because all athletes could manage to exercise for at least 1 hour. Supramaximal intensity $(120 \%$ of $\mathrm{VO}_{2 \max }$ ) would recruit energy from both aerobic and anaerobic sources [17], suggesting different metabolic response between the two exercise protocols. Exercise intensity was calculated based on the equation of power $(\mathrm{kg})$ against $\%$ of $\mathrm{VO}_{2}$ in submaximal tests, and from the equation of time spent at $40^{\prime \prime}$ and $20^{\prime \prime}$ [(OBLA+ (5\%of OBLA x OBLA)- $\left.\left(0.33^{\star} 40 \%\right)\right] / 0.66$. The pedaling frequency was set at $70 \mathrm{rpm}$ and maintained through both tests (both the slow and fast parts of the ALT exercise) with the aid of digital display adjusted to the bike. Furthermore, an assistant was verbally giving feedback to the participants.

Both protocols were conducted under the same environmental conditions (temperature of $20^{\circ} \mathrm{C}-22^{\circ} \mathrm{C}$, and relative humidity of 45 $50 \%)$.

\section{Measurements}

Body composition: Percent of body fat was estimated by measuring skinfold thickness at four sites (biceps, triceps, suprailiac, subcapular) using a caliper [18].

Ventilatory parameters: $\mathrm{VO}_{2}, \mathrm{VE}$, and $\mathrm{R}$ were measured breath by breath. In both main trials (ALT and CON exercise) the ventilatory parameters were measured continuously during the first 10 minutes of the exercise and then continuously for the last 3 minutes of each of the remaining 10 minute intervals, until the completion of the exercise.

Lactate analysis (La): $20 \mu \mathrm{l}$ capillary blood from fingertips was collected at rest, 5, 10, 15, 20, 30, 40, 50 and 60 minutes for lactate concentration. The analysis of the lactate was made photometrically (Jenway, 3600, UK, [19]).

Heart rate was measured continuously throughout the tests with Polar (Sports Tester, Filand). Each test performed with the same HR monitor.

Borg scale: The subject perception of exertion during each test was referenced with 6-20 scale [15]. 
Citation: Spanoudaki S, Maridaki M, Karatzanos E, Bogdanis GC, Spanoudaki C, et al. (2012) Comparison of Cardiorespiratory and Hormonal Responses between Sustained Constant and Alternating Intensity Exercise. J Sport Medic Doping Studie 1:103. doi:10.4172/21610673.1000103

Page 3 of 6

\section{Venous blood sampling}

Venous blood samples were drawn from an antecubital vein from each participant, in the sitting position, at the following times: prior to test, during the last seconds of 30 and 60 minutes of exercise and 1 hour after the end of exercise. Changes of plasma volume were calculated from Hemoglobin and Hematocrit according to Dill and Costil [20] equations.

\section{Hormones}

For Nor- adrenaline (NADR) and adrenaline (ADR) measurement, $2 \mathrm{ml}$ of blood for each hormone was collected into EDTA tubes and centrifuged and the plasma stored at $-70^{\circ} \mathrm{C}$ until analysis. The concentration of each catecholamine was measured using the commercially available Elisa Kit (Biosource, Belgium, KAPL 10-200, KAPL 10-0100). The intra- and interassay coefficients of variation have been reported to be less than $5.2 \%$ and $7.0 \%$, respectively

For Growth Hormone analysis (GH), serum was separated from whole blood by centrifugation at $1000 \mathrm{~g}$ for $10 \mathrm{~min}$ at room temperature, then, stored at $-70^{\circ} \mathrm{C}$ until analysis was conducted. The concentration of growth hormone was measured using the commercially available Elisa Kit (Biosource, Belgium, KAP1081). The intra- and interassay coefficients of variation have been reported to be less than $9.8 \%$ and $15 \%$, respectively.

Hematocrit - Hemoglobin: were measured via routine methods (ABBOT, USA).

\section{Statistical analysis}

Data are presented as means and $\pm \mathrm{SD}$. Differences between the two conditions over time were analyzed using two-way ANOVA with repeated measures. In case a statistical significance was detected, a Tukey - Post Hoc Test was conducted for multiple comparisons. Statistical analysis was performed using Statistica V.8, the level of significance was set at $\mathrm{p}<0.05$. Power analysis was conducted by commercial available software ( $G^{*}$ Power 3.1 , Germany), level was set at 0.8 level.

\section{Results}

Performance baseline characteristics of the subjects were: $\mathrm{VO}_{2 \max }$ : $47.9 \pm 6.5 \mathrm{ml} / \mathrm{kg} / \mathrm{min}$, HRmax: $188 \pm 12 \mathrm{~b} / \mathrm{min}$, maximal power (POmax): $267 \pm 18$ Watts and $\mathrm{VO}_{2}$ at LT: $32.3 \pm 5.0 \mathrm{ml} / \mathrm{kg} / \mathrm{min}$. Mean PO for CON was $154 \pm 17$ Watts, $(57.8 \pm 6.5 \%$ POmax), while mean PO for ALT was $158.8 \pm 20.5$ Watts, $(59.4 \pm 7.8 \%$ POmax). No difference was found between the two exercise protocols concerning PO, either in relative or absolute values, $(\mathrm{p}=0.12)$.

\section{Cardiorespiratory and metabolic parameters}

Oxygen uptake $\left(\mathrm{VO}_{2}\right)$ was affected by the type of exercise, with higher $\mathrm{VO}_{2}$ in $\mathrm{CON}$ compared to ALT exercise, (32.5 \pm 6.6 vs. $29.8 \pm 5.9$ $\mathrm{ml} / \mathrm{kg} / \mathrm{min}, \mathrm{p}<0.05$, see Figure 1$). \mathrm{VO}_{2}$ was also, affected by the time ( $<<0.01$, see Figure 1 and increased in both CON and ALT over time). Similarly, HR was overall higher in CON compared to ALT exercise, (152 \pm 16 vs. $142 \pm 15 \mathrm{~b} / \mathrm{min}$, see Figure 2). The type of exercise had no effect on VE ( $\mathrm{p}=0.55$, see Figure 3 ) or on the R value ( $\mathrm{p}=0.42$, see Figure 4). There was a drift in $\mathrm{VO}_{2}, \mathrm{HR}$ and VE showing a gradual increase, while R showed a gradual decrease over time (Figures 1-4).

Changes in blood lactate concentration for CON and ALT are shown in Figure 5. Lactate concentration increased over time $(p<0.01)$ in both exercise conditions, but there were no significant differences between the two protocols $(\mathrm{p}=0.75)$.

\section{Hormonal parameters}

There were no significant differences in plasma volume changes between CON and ALT from rest to the 30th minute $(p=0.11)$, from rest to the 60th minute of exercise $(\mathrm{p}=0.33)$ and from rest to 1 hour post-exercise $(p=0.36)$. Table 1 shows the changes in hormone

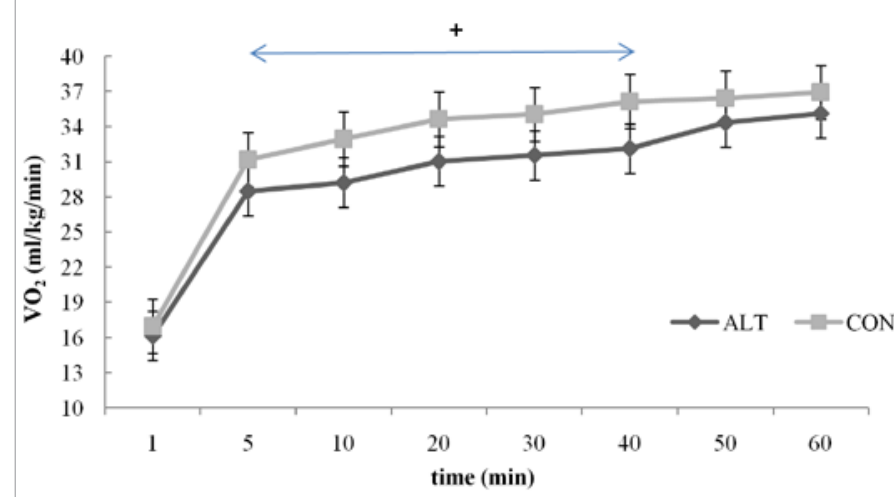

+ significant difference between CON and ALT at 5, 10,30, and 40 minutes $(p<0.05)$.

Figure 1: Changes in $\mathrm{VO}_{2}$ (mean $\pm \mathrm{SD}$ ) in constant and alternating intensity exercise.

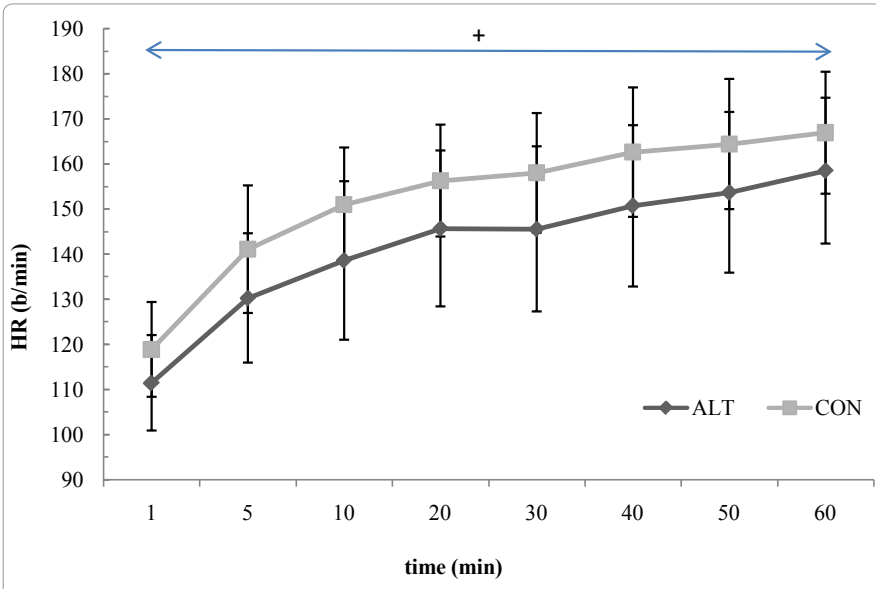

+ significant difference between CON and ALT $(p<0.05)$.

Figure 2: Changes in HR (mean $\pm \mathrm{SD}$ ) in constant and alternating intensity exercise.

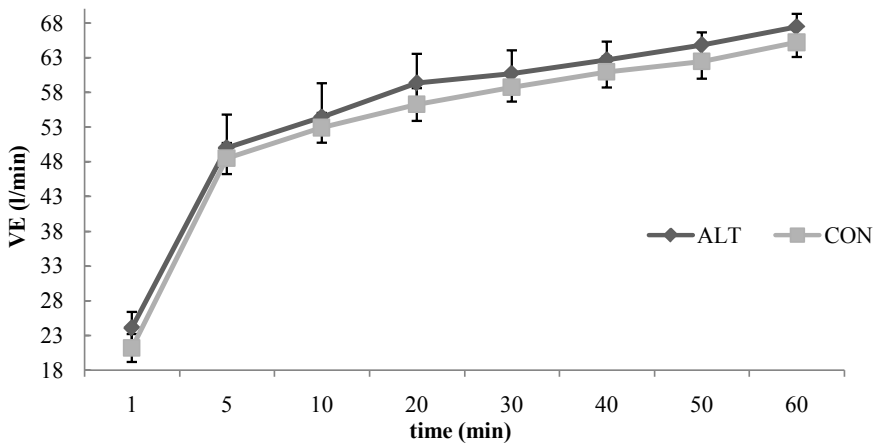

Figure 3: Changes in VE (mean $\pm \mathrm{SD}$ ) in constant and alternating intensity exercise. 
Citation: Spanoudaki S, Maridaki M, Karatzanos E, Bogdanis GC, Spanoudaki C, et al. (2012) Comparison of Cardiorespiratory and Hormonal Responses between Sustained Constant and Alternating Intensity Exercise. J Sport Medic Doping Studie 1:103. doi:10.4172/21610673.1000103

Page 4 of 6

concentration in CON and ALT. There was no difference between CON and ALT in the changes of ADR ( $p=0.22)$, and GH $(p=0.80)$, but there were significant main effects for time $(\mathrm{p}<0.01)$. ADR and $\mathrm{GH}$ increased at 30 and 60 minute of exercise and returned to the resting values 1 hour post exercise (Table 1). Changes in NADR concentration were affected by the type $(\mathrm{p}=0.05)$ of exercise and by time $(\mathrm{p}<0.01)$ with values in CON being higher than values in ALT. The NADR concentration was increased from rest over time and returned to resting value 1 hour post exercise (Table 1). For all 3 hormones examined, higher values were observed at the $30^{\text {th }}$ and $60^{\text {th }}$ min of exercise in comparison to rest ( $\mathrm{p} \leq 0.01$ ), but no differences were observed between rest and 1 hour post exercise ( $\mathrm{p}>0.05)$. For NADR and GH there were also significant difference between the $30^{\text {th }}$ and $60^{\text {th }}$ min of exercise $(\mathrm{p} \leq 0.05)$.

In relation to type of exercise and the interaction of 'time by type', power analysis showed that sample size is not a confounding factor (ADR: 0.22; 0.12, GH: 0.06; 0.05, VE: 0.05; 0.25, for type and 'time by type' respectively). This was not the case for La concentration (power: 0.06 for time, 0.56 for time by type) and $\mathrm{R}$ (power: 0.12 for type, 0.54 for time by type), for which, power analysis showed that some differences in time by type interaction could be found increasing the sample size.

Borg Scale: We found no differences between the two exercise protocols concerning the type and the time $(p=0.35$, and $p=0.30$ accordingly, see Figure 6).

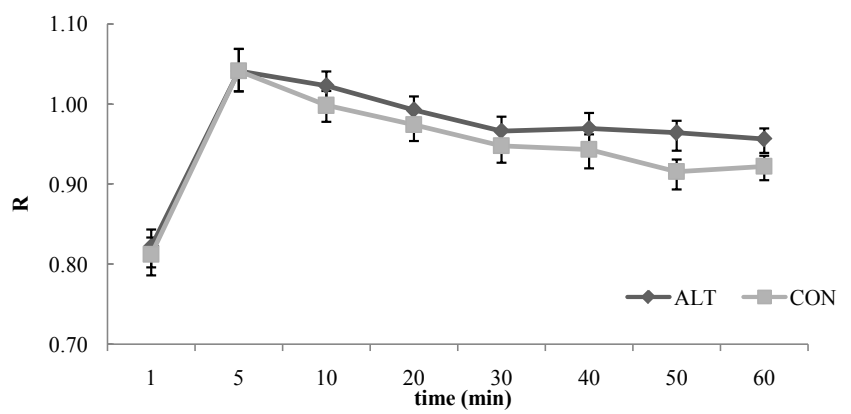

Figure 4: Changes in $\mathrm{R}$ (mean $\pm \mathrm{SD}$ ) in constant and alternating intensity exercise.

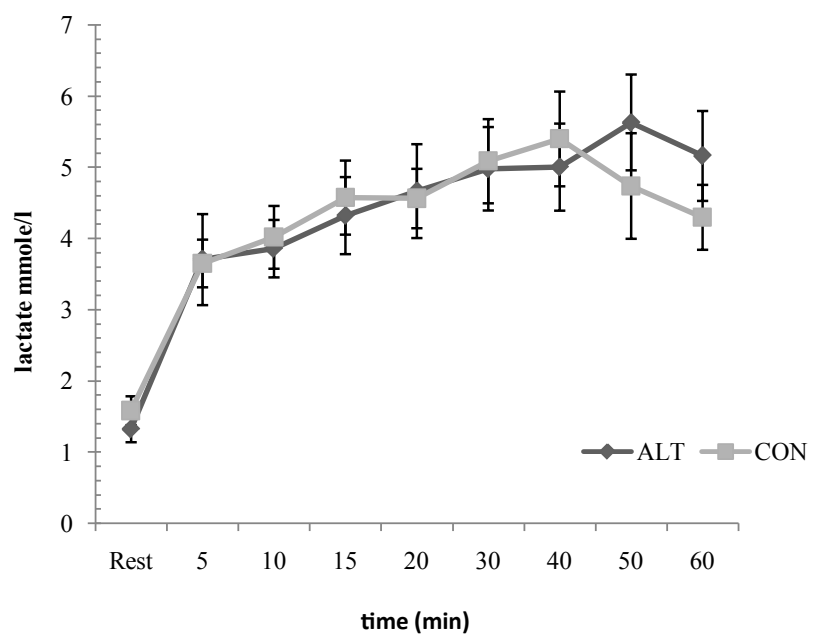

Figure 5: Changes in blood lactate concentration (mean \pm SD) in constant and alternating intensity exercise.

\begin{tabular}{|c|c|c|c|c|c|}
\hline Variable & Rest & $30^{\prime}$ & $60^{\prime}$ & $120^{\prime}$ & $\mathrm{P}$ \\
\hline \multicolumn{6}{|c|}{ Adrenaline (ng/ml) } \\
\hline $\begin{array}{l}\text { Alternating } \\
\text { Intensity }\end{array}$ & $0.03 \pm 0.03$ & $0.14 \pm 0.07$ & $0.20 \pm 0.08$ & $0.05 \pm 0.03$ & \multirow{2}{*}{$<0.01 ; 0.23$} \\
\hline $\begin{array}{l}\text { Constant } \\
\text { Intensity }\end{array}$ & $0.03 \pm 0.01$ & $0.14 \pm 0.05$ & $0.17 \pm 0.10$ & $0.04 \pm 0.04$ & \\
\hline \multicolumn{6}{|c|}{ Nor-Adrenaline (ng/ml) } \\
\hline $\begin{array}{l}\text { Alternating } \\
\text { Intensity }\end{array}$ & $0.62 \pm 0.48$ & $1.98 \pm 1.30$ & $3.30 \pm 1.65$ & $0.84 \pm 0.57$ & \multirow{2}{*}{$<0.01 ; 0.05$} \\
\hline $\begin{array}{l}\text { Constant } \\
\text { Intensity }\end{array}$ & $0.79 \pm 0.28$ & $3.03 \pm 1.05$ & $3.70 \pm 2.06$ & $1.21 \pm 0.76$ & \\
\hline \multicolumn{6}{|c|}{ Growth Hormone (ng/ml) } \\
\hline $\begin{array}{l}\text { Alternating } \\
\text { Intensity }\end{array}$ & $0.38 \pm 0.34$ & $3.62 \pm 3.13$ & $7.83 \pm 4.34$ & $0.77 \pm 0.57$ & \multirow{2}{*}{$<0.01 ; 0.80$} \\
\hline $\begin{array}{l}\text { Constant } \\
\text { Intensity }\end{array}$ & $0.34 \pm 0.37$ & $3.47 \pm 3.80$ & $7.50 \pm 6.40$ & $0.69 \pm 0.81$ & \\
\hline
\end{tabular}

The first $p$ value represents the time effect; the second $p$ value represents the type (continuous versus intermittent) $x$ time interaction

Table 1: Plasma catecholamines and serum growth hormone changes (mean \pm $\mathrm{SD}$ ) before, 30 and $60 \mathrm{~min}$ of exercise and 1 hour after the end of exercise (ALTCON).

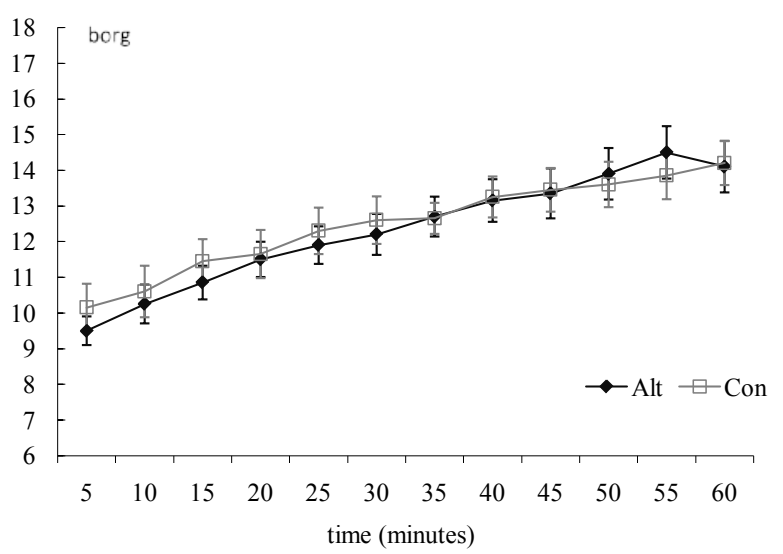

Figure 6: Changes in Borg Scale (mean \pm SD) in constant and alternating intensity exercise.

\section{Discussion}

The main finding of the present study was that during sustained exercise slightly above the lactate threshold, $\mathrm{VO}_{2}, \mathrm{HR}$ and NADR were higher in the CON compared with the ALT condition. In contrast, large fluctuations of exercise intensity (power corresponding to $47 \%$ $120 \% \mathrm{VO}_{2 \max }$ ) did not alter the time course of $\mathrm{VE}$ and $\mathrm{R}$ value, lactate, $\mathrm{ADR}$ and $\mathrm{GH}$ concentration from that observed in the CON exercise protocol (power corresponding to $70 \% \mathrm{VO}_{2 \max }$ ).

Our data differed from the findings of Essen et al. [3,4], who found that cycling for 60 minutes continuously or with alternating intensity (15 sec work - $15 \mathrm{sec}$ rest) with identical average power output and mean intensity corresponding to $50-55 \%$ of $\mathrm{VO}_{2 \max }$, resulted in similar cardiorespiratory response. Also, differed from other studies, who found that $\mathrm{R}$ and blood lactate concentration were higher in intermittent compared to continuous exercise, while there were no differences in HR response [21,22]. In these protocols, exercise either lasted 30 minutes with mean intensity corresponding to $90 \%$ of the Lactate Threshold, or they cycled for 1 hour to $78 \%$ of $\mathrm{VO}_{2 \max }$, In addition, other investigators showed that interval running (1- to $60 \mathrm{sec}$ work altered with 20 to $120 \mathrm{sec}$ rest) caused lower lactate concentration compared to running continuously to exhaustion with the same 
Citation: Spanoudaki S, Maridaki M, Karatzanos E, Bogdanis GC, Spanoudaki C, et al. (2012) Comparison of Cardiorespiratory and Hormonal Responses between Sustained Constant and Alternating Intensity Exercise. J Sport Medic Doping Studie 1:103. doi:10.4172/21610673.1000103

Page 5 of 6

amount of work [23], or found no difference on lactate concentration and $\mathrm{VO}_{2}$ when constant and alternating intensity exercise performed with the same power output corresponding to $90 \%$ of critical power and to 75 Watt $[24,25]$.

The controversial results between the previous studies and our study are possibly due to methodological differences in exercise protocol depending on the purpose of each study. There were differences in exercise protocols concerning the type of exercise, cycling vs running, the overall intensity, fluctuating from $50 \%$ to $120 \%$ of $\mathrm{VO}_{2 \max }$, exercise duration and ratio of intense exercise and rest/or lower impact exercise. Another explanation could be the different substrate utilization between the studies. Essen et al. [3,4] found that lipid metabolism was higher in intermittent exercise compared to constant. Others [26,27] showed that fat oxidation was 3 times lower in intermittent exercise compared to continuous submaximal exercise, despite similar overall $\mathrm{VO}_{2}$, when running at $70 \%$ of $\mathrm{VO}_{2 \max }$. Earlier studies, mentioned that ATP- CP and oxygen bound to myoglobin were used predominately in intermittent exercise compared to constant with the same workload $[6,7,23]$.

Energy production through ATP-CP system is unlikely to be the main source of energy in ALT exercise, since 40 seconds of low intensity exercise alternated with 20 seconds of supramaximal exercise may not be enough for complete resynthesization of ATP-CP in ALT [24]. VE for exercise intensities above LT is stimulated by metabolic acidosis resulting in lactate accumulation [28]. We found no difference in lactate concentration between the two types of exercise, explaining why VE didn't differ and suggesting that ALT intensity exercise could not place greater stress on anaerobic energy systems than CON exercise. Possibly, the lower intensity during ALT exercise stimulated lactate removal and as a result metabolic acidosis was avoided [29]. $\mathrm{R}$ values, fluctuating between 0.9 and 1 , didn't differ between the two exercise protocols, suggesting that in both protocols energy was supplied by carbohydrate. In intense and non steady state exercise there is an underestimation of fat oxidation with Indirect Calorimetry [30]. Since, we didn't measure carbohydrate, fat oxidation and ATPCP system only speculations we could made. More studies need to be conducted in order to examine the energy source in two exercise regimes. The greater $\mathrm{VO}_{2}$ in $\mathrm{CON}$ exercise could not be explained by environmental condition and water supply during exercises, because both were kept constant in both studies. The variations in $\mathrm{VO}_{2}$ and HR response between the two types of exercise could be explained by the different kinetics. Morris et al. [8], showed that the slower kinetics of $\mathrm{HR}$ and $\mathrm{VO}_{2}$ in alternating exercise caused lower $\mathrm{VO}_{2}, \mathrm{VE}$ and $\mathrm{HR}$ values compared to constant exercise. Probably, the lower values in $\mathrm{VO}_{2}$ and $\mathrm{HR}$ response in $\mathrm{AL}$ compared to $\mathrm{CON}$ may reflect a delay on kinetics from light to supramaximal exercise. On the contrary, Dorado et al. [31], mentioned that active recovery $\left(20 \%\right.$ of $\left.\mathrm{VO}_{2 \max }\right)$ between high intensity intermittent cycling for two minutes and corresponding to $120 \%$ of $\mathrm{VO}_{2 \max }$ caused greater contribution of aerobic metabolism due to faster $\mathrm{VO}_{2}$ kinetics. Our results differ from Dorado et al. [31], because in our protocol the alternating intensity exercise was longer, lasting 1 hour and the alterations between 40 " of light exercise with only $20^{\prime \prime}$ of intense exercise may not be enough for changes in $\mathrm{VO}_{2}$ kinetics.

The higher HR and NADR response in CON exercise suggests greater demand on the cardiovascular system compared to ALT. Despite the significant difference between the two protocols concerning the NADR concentration, more studies need to be conducted in order to examine the NADR response because of the large standard deviation in ALT values at the $30^{\text {th }}$ minute of exercise.

We found that the concentration of ADR and GH did not differ between the two exercise protocols. Our results are in line with the study of Nieman et al. [11], who examined 2 hours cycling at $64 \%$ of Wattmax continuously or with 3 minutes rest interspersed every 10 minutes. They showed that the concentration of cortisol and ADR was the same either in constant or alternating intensity cycling. The concentration of GH in intermittent exercise was higher [12], or there was no difference [13] when compared to constant. The differences may be attributed to different exercise protocol. In one study the duration of exercise was 20 minutes, while in the other was 40 minutes, and the intensity was set at 150 watt and $45 \%$ of the minimum load which elicit $\mathrm{VO}_{2 \max }$ accordingly (shorter duration and different exercise intensity).

ADR and NADR regulate cardiovascular and metabolic functions, and their blood levels reflect sympatho-adrenal activity [10]. Adrenaline level is supposed to represent emotional stress, while NADR reflects physical stress [32]. The fact that we found no differences in ADR concentration between the two types of exercise maybe explained by the rate of perceived exertion, ALT and CON exercise had similar RPE, indicating that subjects when exercising at the same average intensity did not perceive ALT as more or less stressful. So, the concentration of ADR, GH, and Cortisol [16] did not seem to be influenced by the type of exercise when mean intensity and duration are similar.

\section{Limitations}

These results could not be applied in different exercise protocols, (different ratio of intense - light exercise, duration and mean intensity) in which the stress and cardiorespiratory demand could be different.

\section{Conclusions}

Our study showed that $\mathrm{VO}_{2} \mathrm{HR}$ response and NADR concentration was higher in CON exercise compared to ALT exercise of the same average intensity and duration, suggesting that CON exercise evoke greater demand on the cardiovascular system. On the other hand, stress hormones, (ADR and GH concentration) did not differ between the two exercise protocols, implying that both protocols are equally stressful. These findings could be applied in designing exercise training programs in various sports and disciplines.

\section{Acknowledgements}

We would like to acknowledge Prof. M. Koutsilieri (MD, PhD), Director of Experimental Physiology Laboratory and Anastasio Philipou (PhD) for their technical support on hormonal analysis.

\section{References}

1. Laursen PB, Jenkins DG (2002) The scientific basis for high intensity interval training: optimizing training programmes and maximising performance in highly trained endurance athletes. Sports Med 32: 53-73.

2. Zafeiridis A, Sarivasiliou H, Dipla K, Vrabas IS (2010) The effect of heavy continuous versus long and short intermittent aerobic exercise protocol on oxygen consumption, heart rate and lactate responses in adolescents. Eur J Appl Physiol 110: 17-26.

3. Essen B, Hagenfeld L, Kaijser L (1977) Utilization of blood -borne and intramuscular substrates during continuous and intermittent exercise in man J Physiol 265: 489-506.

4. Essen B (1978) Glycogen depletion of different fibre types in human skeleta muscle during intermittent and continuous exercise. Acta Physiol Scand 103 446-455. 
Citation: Spanoudaki S, Maridaki M, Karatzanos E, Bogdanis GC, Spanoudaki C, et al. (2012) Comparison of Cardiorespiratory and Hormonal Responses between Sustained Constant and Alternating Intensity Exercise. J Sport Medic Doping Studie 1:103. doi:10.4172/2161. 0673.1000103

Page 6 of 6

5. Palmer GS, Borghouts LB, Noakes TD, Hawley JA (1999) Metabolic and performance responses to constant- load vs. variable - intensity exercise in trained cyclists. J Appl Physiol 87: 1186-1196.

6. Astrand I, Astrand PO, Christensen EH, Hedman R (1960) Intermittent Muscular Work. Acta Physiol Scand 48: 448-453.

7. Christensen EH, Hedman R, Saltin B (1960) Intermittent and Continuous Running Acta Physiol Scand 50: 269-286.

8. Morris M, Gass G, Thompson M, Confort D (2003) Physiological responses to intermittent and continuous exercise at the same relative intensity in older men. Eur J Appl Physiol 90: 620-625.

9. Edwards RH, Ekelund LG, Harris RC, Hesser C, Hultman E, et al. (1973) Cardiorespiratory and metabolic costs of continuous and intermittent exercise in man. J Physiol 234: 481-497.

10. Kindermann W, Schnabel A, Schmitt WM, Biro G, Cassens J, et al. (1982) Catecholamines, growth hormones, cortisol, insulin, and sex hormones in anaerobic and aerobic exercise. Eur J Appl Physiol Occup Physiol 49: 389-399.

11. Nieman D, Henson D, Gojanovich G, Davis J, Dumke C, et al. (2007) Immune changes: 2 h of continuous vs Intermittent cycling. Int J Sports Med 28: 625630 .

12. Karagiorgos A, Garcia JF, Brooks GA (1979) Growth hormone response to continuous and intermittent exercise. Med Sci Sports 11: 302-307.

13. Weltman A, Weltman JY, Watson WD, Frick K, Patrie J, et al. (2008) Effects of continuous versus intermittent exercise, obesity, and gender on growth hormone secretion. J Clin Endocrinol Metabol 93: 4711-4720.

14. Bogdanis GC, Papaspyrou A, Theos A, Maridaki M (2007) Influence of resistive Load on power output and fatigue during intermittent sprint cycling exercise in children. Eur J Appl Physiol 101: 313-320.

15. Bird S, Davison R (1997) The British Association of Sport and Exercise Sciences, $3^{\text {rd }}$ Edition. In Physiological Testing Guidelines. Determination of the lactate threshold and the onset of blood lactate accumulation data, (pp 68-70), the use of effort perception, (pp 71-72).

16. Spanoudaki S, Maridaki M, Tsironi M, Baltopoulos G, Bogdanis G, et al. (2010) Immune responses during and after exercise of constant and alternating intensity above the lactate threshold. J Sports Med Phys Fitness 50: 363-370.

17. Hargreaves M, Mckenna MJ, Jenkins DG, Warmington SA, Li JL, et al. (1998) Muscle metabolites and performance during high- intensity, intermittent exercise. J Appl Physiol 84: 1687-1691.

18. Durnin RV, Rahaman MM (1967) The assessment of the amount of fat in the human body for measurements of skinfold thickness. Brit J Nutr 21: 681-689.

19. Maughan RJ, Williams C, Campbell DM, Hepburn D (1978) Fat and carbohydrate metabolism during low intensity exercise: effects of the availability of muscle glycogen. Eur J Appl Physiol Occup Physiol 39: 7-16.

20. Dill DB, Costill DL (1974) Calculation of percentage changes in volumes of blood, plasma and red cells in dehydration. J Appl Physiol 37: 247-248.

21. Suriano R, Vercruyssen F, Bishop D, Brisswalter J (2007) Variable powe output during cycling improves subsequent treadmill run time to exhaustion. J Sci Med Sport 10: 244- 251.

22. Liedl M, Swain D, Branch JD (1999) Physiolagical effects of constant versus variable power during endurance cycling. Med Sci Sports Exerc 31: 1472-1477.

23. Fox E, Robinson S, Wiegman DL (1969) Metabolic energy sources during continuous and interval running. J Appl Physiol 27: 174-178.

24. Brickley G, Green S, Jenkins DG, McEinery M, Wishart C, et al. (2007) Muscle Metabolism during constant- and alternating-intensity exercise around critical power. Int J Sports Med 28: 300-305.

25. Kang J, Mangine GT, Ratamess NA, Faigenbau AD, Hoffman JR (2007) Infleunce of intensity fluctuation on exercise metabolism. Eur J Appl Physio 100: 253-260.

26. Christmass MA, Dawson B, Arthur PG (1999) Effect of work and recovery duration on skeletal muscle oxygenation and fuel use during sustained intermittent exercise. Eur J Appl Physiol Occup Physiol 80: 436-447.

27. Christmass MA, Dawson B, Passeretto P, Arthur PG (1999) Comparison of skeletal muscle oxygenation and fuel use in sustained continuous and intermittent exercise. Eur J Appl Physiol Occup Physiol 80: 423-435.

28. Wassermann K, Beaver WL, Whipp BJ (1990) Gas exchange theory and the lactic acidosis (anaerobic) threshold. Circulation 81: 14-30.

29. Brooks GA, Fahey TD White TP (1996) Exercise Physiology. Mayfield Publishing, Company, Mountain View, CA.

30. Romijn JA, Coyle EF, Hibbert J, Wolfe RR (1992) Comparison of indirect calorimetry and a new breath $13 \mathrm{C} / 12 \mathrm{C}$ ratio method during strenuous exercise. Am J Physiol 263: E64-E71.

31. Dorado C, Sanchis-Moysi J, Calbet JA (2004) Effects of recovery mode on performance $\mathrm{O}_{2}$ uptake, and $\mathrm{O}_{2}$ deficit during high- intensity intermittent exercise. Can J Appl Physiol 29: 227-244.

32. Pierce D, Kupprat I, Harry D (1976) Urinary epinephrine and norepinephrine levels in women athletes during training and competition. Eur J Appl Physio Occup Physiol 36: 1-6. 